\section{Alveolar Macrophage Replication \\ One Mechanism for the Expansion of the Mononuclear Phagocyte Population in the Chronically Inflamed Lung}

Peter B. Bitterman, Lori E. Saltzman, Steven Adelberg, Victor J. Ferrans, and Ronald G. Crystal Pulmonary Branch and Pathology Branch, National Heart, Lung and Blood Institute, National Institutes of Health, Bethesda, Maryland 20205 bstract. Within any chronically inflamed tissue, there is an increased number of macrophages, pluripotential phagocytic cells that, while critical to host defenses, are also able to profoundly damage parenchymal structure and function. Because of their central role in the inflammatory response, considerable attention has been focused on the mechanisms resulting in an expansion of the macrophage population within an inflamed tissue. Although recruitment of precursor monocytes from the circulation into inflamed tissues clearly plays an important role in macrophage accumulation, it is also possible that replication of tissue macrophages contributes to the expansion of macrophage numbers in inflammation. Because of the accessibility of tissue macrophages with the technique of bronchoalveolar lavage, the lung provides an ideal opportunity to test this hypothesis in humans. To accomplish this, bronchoalveolar lavage was performed to obtain alveolar macrophages from normals ( $n$ $=5$ ) and individuals with chronic lung inflammation (normal smokers $[n=5$ ], idiopathic pulmonary fibrosis [ $n=13$ ], sarcoidosis [ $n=18$ ], and other chronic interstitial lung disorders $[n=11])$. Alveolar macrophage replication was quantified by three independent methods: (a) DNA synthesis, assessed by autoradiographic analysis of macrophages cultured for $16 \mathrm{~h}$ in the presence of $\left[{ }^{3} \mathrm{H}\right]$ thymidine; (b) DNA content, assessed by flow cytometric analysis of macrophages fixed immediately after recovery from the lower respiratory tract; and (c) cell division, assessed by cluster formation in semisolid medium. While the proportion of replicating macrophages

Address reprint requests to Dr. Bitterman, National Institutes of Health, Building 10, Room 6D20, Bethesda, MD 20205.

Received for publication 6 February 1984 and in revised form 12 April 1984.

The Journal of Clinical Investigations, Inc.

Volume 74, August 1984, 460-469 in normals was very low, there was a 2-to 15 -fold increase in this proportion in patients with chronic lung inflammation. In addition, morphologic evaluation demonstrated that individuals with chronic lung inflammation had alveolar macrophages undergoing mitosis. These results suggest that local tissue macrophage replication may play a role in the expansion of the macrophage population in chronic inflammation.

\section{Introduction}

Tissue macrophages are phagocytic, monocyte-derived cells thought to play a major role in host defense (1-4). It is well recognized, however, that tissue macrophages also have the potential to damage an organ by virtue of their ability to release oxidants $(5,6)$, proteases $(7,8)$, chemoattractants for other inflammatory cells $(9,10)$, and growth factors that signal fibroblasts to replicate (11-15). In this context, it is easy to understand how the continued presence of large numbers of macrophages within an organ, such as occurs in chronic inflammatory disorders, may play a central role in the modification of tissue structure and function that accompanies such disorders.

One concept of the regulation of macrophage numbers within an organ is that it results from a balance between the rate of recruitment of blood monocytes to the organ and the rate of macrophage efflux (including cell death) from that organ (16). According to this concept, the increased numbers of macrophages within a chronically inflamed tissue results from an increased rate of recruitment of monocytes to the inflamed site.

An alternative, not necessarily mutually exclusive, explanation is that the increased numbers of macrophages found within a tissue in association with chronic inflammation may result, at least in part, from an increased rate of replication of macrophages in situ. If this is the case, then the concepts of the pathogenesis and therapeutic intervention in many chronic inflammatory diseases would require modification to include the notion that the rate of macrophage replication may have an important influence on the outcome of chronic inflammatory processes.

The chronic inflammatory lung diseases afford a unique 
Table I. Summary of Clinical, Physiologic, and Bronchoalveolar Lavage Parameters of the Study Population

\begin{tabular}{|c|c|c|c|c|c|c|c|c|c|c|c|c|}
\hline \multirow[b]{2}{*}{ Group } & \multirow[b]{2}{*}{$n$} & \multirow[b]{2}{*}{ Age } & \multirow{2}{*}{$\begin{array}{l}\text { Sex } \\
(M / F)\end{array}$} & \multirow{2}{*}{$\begin{array}{l}\text { Nonsmoker/ } \\
\text { smoker }\end{array}$} & \multicolumn{4}{|c|}{ Pulmonary function tests* } & \multicolumn{4}{|c|}{ Bronchoalveolar lavageł } \\
\hline & & & & & vc & TLC & DCO & FEV,$\%$ & $\mathbf{M}$ & $\mathbf{L}$ & $\mathrm{N}$ & $\mathbf{E}$ \\
\hline Normals & 5 & $23 \pm 4$ & $2 / 3$ & $5 / 0$ & $93 \pm 4$ & $102 \pm 5$ & $93 \pm 4$ & $98 \pm 6$ & $95 \pm 4$ & $5 \pm 1$ & 0 & 0 \\
\hline Normal smokers & 5 & $22 \pm 3$ & $2 / 3$ & $0 / 5$ & $95 \pm 4$ & $101 \pm 6$ & $97 \pm 4$ & $97 \pm 7$ & $94 \pm 4$ & $6 \pm 2$ & 0 & 0 \\
\hline IPF & 13 & $49 \pm 5$ & $8 / 5$ & $7 / 6$ & $56 \pm 5$ & $47 \pm 6$ & $55 \pm 5$ & $102 \pm 8$ & $84 \pm 6$ & $6 \pm 3$ & $9 \pm 2$ & $1 \pm 1$ \\
\hline Sarcoidosis & 18 & $38 \pm 4$ & $7 / 11$ & $13 / 5$ & $71 \pm 4$ & $75 \pm 5$ & $77 \pm 6$ & $96 \pm 6$ & $76 \pm 7$ & $22 \pm 4$ & $1 \pm 1$ & $1 \pm 1$ \\
\hline \multicolumn{13}{|l|}{ Other interstitial } \\
\hline lung disorders & 11 & $51 \pm 9$ & $7 / 4$ & $4 / 7$ & $67 \pm 12$ & $70 \pm 11$ & $65 \pm 13$ & $99 \pm 5$ & $82 \pm 12$ & $9 \pm 7$ & $5 \pm 4$ & $4 \pm 3$ \\
\hline
\end{tabular}

* VC, vital capacity; TLC, total lung capacity (He equilibration); DCO, carbon monoxide diffusing capacity (corrected for alveolar volume and hemoglobin); FEV $\%$, forced expiratory volume in $1 \mathrm{~s} /$ forced vital capacity $\times 100$. All values are expressed as percent predicted. $¥$ Data determined by cytocentrifuge preparations of recovered cells. Values are expressed as percentage of total cells recovered. M, macrophages; L, lymphocytes; N, neutrophils; and E, eosinophils.

opportunity to determine whether human macrophages replicate within tissues and whether the rate of macrophage replication is increased in chronic inflammation. Not only are most chronic inflammatory lung disorders characterized by increased numbers of alveolar macrophages (17-22), but most importantly, these macrophages can be easily recovered for study.

In this context, the purpose of the present investigation was to determine if human alveolar macrophages are capable of replicating, and to assess the rate of replication of alveolar macrophages in situations characterized by chronic inflammation. The results indicate that human alveolar macrophages are capable of replicating, and in addition, the proportion of alveolar macrophages that are replicating is markedly increased in diverse conditions characterized by an increase in the numbers of macrophages within the alveolar structures.

\section{Methods}

Study population. The study population included 52 individuals evaluated on the Pulmonary Branch Clinical Service at the Clinical Center, National Institutes of Health (Table I). Because the number of alveolar macrophages available from each subject was not always sufficient to carry out all studies, in some instances, different numbers of subjects were included in each group; the exact number for a given study can be determined from each graph where the data is plotted as an individual point for each subject.

Normals. This group consisted of five nonsmokers. None had a history of chronic respiratory symptoms. All had normal physical examinations, chest roentgenograms, lung function tests, and bronchoalveolar lavage analyses.

Normal smokers. This group included five current cigarette smokers with no respiratory symptoms. On the average (all data are presented as mean $\pm \mathrm{SE}$ of the mean), the group smoked $5 \pm 2$ pack-years. They all had normal physical examinations, chest roentgenograms, lung function tests, and bronchoalveolar lavage cell differentials. However, consistent with previous reports $(23,24)$, there was about a threefold increase in the number of macrophages recovered by the standard bronchoalveolar lavage procedure (normal, $160 \pm 22$ cells/ml recovered; smokers, $410 \pm 38$ cells $/ \mathrm{ml}$ recovered, $P<0.01)$ i.e., these individuals had chronic inflam- mation with increased numbers of macrophages in their lower respiratory tract. This group of young, short-term smokers was included to evaluate the consequences of smoking per se on the rate of macrophage replication in the absence of apparent derangements to the alveolar structures.

Idiopathic pulmonary fibrosis (IPF).' This group consisted of 13 individuals with a diagnosis of IPF made by previously defined criteria including open lung biopsy (25). The clinical, roentgenographic, physiologic, and bronchoalveolar lavage findings were typical of IPF patients in the early to mid-course of their disease. Eight patients were receiving prednisone $(31 \pm 6 \mathrm{mg} / \mathrm{d})$ and five were not on therapy.

Sarcoidosis. This group included 18 individuals with a diagnosis of pulmonary sarcoidosis made by previously defined criteria, including lung or thoracic lymph node biopsy (26). The clinical, roentgenographic, physiologic, and bronchoalveolar lavage findings were typical of an average group of patients with chronic pulmonary sarcoidosis. 8 patients were receiving prednisone $(26 \pm 6 \mathrm{mg} / \mathrm{d})$ and 10 were not being treated.

Other chronic interstitial lung disorders. This group included a variety of chronic interstitial lung disorders including histiocytosis $X(n=4)$, asbestosis $(n=3)$, and coal worker's pneumoconiosis $(n=4)$. Histiocytosis $\mathbf{X}$ was diagnosed using previously defined criteria including open lung biopsy (27). Asbestosis and coal worker's pneumoconiosis were diagnosed by a history of exposure, chest roentgenographic abnormalities, and typical clinical and physiologic abnormalities $(28,29)$.

Bronchoalveolar lavage. To obtain alveolar macrophages from the study population, each patient underwent bronchoalveolar lavage (30) with a total of five $20-\mathrm{ml}$ aliquots of sterile $0.9 \%$ saline in each of three sites. The cells were recovered from the lavage fluid by centrifugation, washed twice in RPMI-1640 (Microbiological Assoc., Walkersville, MD), and counted by hemocytometer. Cell differentials were performed on cytocentrifuge preparations stained with Diff-Quick (American Scientific Products, McGaw Park, IL). The viability of the alveolar macrophages, as determined by trypan blue exclusion, was $>92 \%$ in all cases.

Evaluation of DNA synthesis by alveolar macrophages. To quantify the proportion of alveolar macrophages synthesizing DNA, standard autoradiographic procedures were employed. Lavage cells from each patient were seeded at $2 \times 10^{5}$ cells/chamber onto Lab-Tek 8 chamber

1. Abbreviations used in this paper: DMEM, Dulbecco's modified Eagle medium; FACS, fluorescence activated cell sorter. IPF, idiopathic pulmonary fibrosis. 
slides (Miles Laboratories Inc., Naperville, IL) in $0.25 \mathrm{ml}$ Dulbecco's modified Eagle medium (DMEM; Gibco Laboratories, Grand Island, $\mathrm{NY}$ ) and cultured for $3 \mathrm{~h}$ at $37^{\circ} \mathrm{C}$ in $90 \%$ air: $10 \% \mathrm{CO}_{2}$. The nonadherent cells were discarded and adherent cells were cultured $\left(16 \mathrm{~h}, 37^{\circ} \mathrm{C}\right)$ in $0.25 \mathrm{ml}$ DMEM, $0.1 \mu \mathrm{Ci} / \mathrm{ml}\left[{ }^{3} \mathrm{H}\right]$ thymidine $(2 \mathrm{Ci} / \mathrm{mmol}$, Amersham Corp., Arlington Heights, IL), $10 \%$ autologous serum (previously incubated $30 \mathrm{~min}, 56^{\circ} \mathrm{C}$ to inactivate complement). In all cases, the $\left[{ }^{3} \mathrm{H}\right]$ thymidine pulsed-adherent cell population consisted of $\geq 95 \%$ alveolar macrophages as assessed by morphology (Diff-Quick), nonspecific esterase staining (31), and phagocytic properties (ingestion of serum opsonized iron particles). Alveolar macrophages were fixed with methanol:acetic acid $\left(3: 1,4^{\circ} \mathrm{C}, 15 \mathrm{~min}\right)$ and then processed for autoradiography (32). The slides were developed for $7 \mathrm{~d}$, and stained with Giemsa blood stain (J. T. Baker Chemical Co., Phillipsburg, NJ). A minimum of 500 cells were evaluated to determine the percentage of alveolar macrophages with labeled nuclei.

Evaluation of the DNA content of alveolar macrophages. To be certain that the alveolar macrophage DNA synthesis observed using autoradiography was directed toward replication and not simply repair synthesis, the amount of DNA present in each macrophage was quantified. To accomplish this, flow cytometry was performed using a fluorescence activated cell sorter (FACS; Becton, Dickinson \& Co., Cockeysville, MD) (33). Briefly, $10^{6}$ lavage cells in $0.3 \mathrm{ml}$ of phosphate-buffered saline, pH 7.4, were fixed by dropwise addition of $0.9 \mathrm{ml}$ of $95 \%$ ethanol. Cells were stained with mithramycin (Pfizer, Clifton, $\mathrm{NJ} ; 0.1 \mathrm{mg} / \mathrm{ml}$ in 150 $\mathrm{mM} \mathrm{NaCl}, 15 \mathrm{mM} \mathrm{MgCl}$ ) and were filtered through $44-\mu \mathrm{m}$ pore nylon mesh to remove clumps. For each sample, at least $10^{4}$ cells were analyzed.

To insure that only alveolar macrophages were evaluated for DNA content, criteria were developed such that the cells being analyzed consisted of $>98 \%$ alveolar macrophages. The major criterion used to choose macrophages was forward light scatter, a parameter that generally correlates with cell size. A forward light scatter profile was determined for each sample. By cell sorting and analysis of the sorted cells with a combination of morphology and ability to phagocytose as criteria, we empirically determined that the peak of cells scattering the most light was composed mostly of alveolar macrophages. The cells scattering more light than the mean scatter value of that peak were invariably $>98 \%$ alveolar macrophages. All analyses of DNA content were performed on a standard sized gate including only this population of cells. The values obtained for the proportion of cells in $G_{1}, S$, or $G_{2}+M$ are therefore relative rather than absolute, but permit comparison of pure alveolar macrophages among patient groups. Unstained lavage cells served to establish the fluorescence base line, which was never found to alter the signal significantly. Density arrested and log phase fibroblasts (HFLl, American Type Culture Collection CCL 153, Rockville, MD) served as an internal standard to precisely identify the channels corresponding to $G_{1}$ and $G_{2}+M$. Determination of the proportion of cells in the various phases of the cell cycle $\left(G_{1}, S\right.$, or $\left.G_{2}+M\right)$ was carried out assuming $G_{1}$ and $G_{2}+M$ were Gaussian populations according to standard methods (34).

Demonstration that some alveolar macrophages entered the M-phase of the cell cycle. To demonstrate that at least some of the alveolar macrophages actually entered the $M$ phase of the cell cycle, macrophages recovered by lavage were evaluated using the technique of metaphase arrest (35). To accomplish this, $2 \times 10^{5}$ macrophages were seeded in $0.2 \mathrm{ml}$ DMEM, $10 \%$ heat-inactivated autologous serum, $2.0 \mu \mathrm{g} / \mathrm{ml}$ colchicine (Sigma Chemical Co., St. Louis, MO) onto Lab-Tek 8 chamber slides. After culture $\left(48 \mathrm{~h}, 37^{\circ}\right)$, cells were prepared for light microscopic visualization of metaphase chromosomes. As further corroboration that alveolar macrophages entered $M$ phase, lung biopsy specimens from patients with chronic inflammatory lung disorders were prepared for ultrastructural evaluation as previously described (36), and examined for alveolar macrophages undergoing mitosis.

Macrophage replication in vitro. To be certain that alveolar macrophages could undergo cytokinesis and divide, an anchorage-independent culture system was employed similar to that used for the culture of bone marrow cells as described by Metcalf (37). Briefly, macrophages were filtered through $44 \mu \mathrm{m}$-mesh to insure a single cell suspension; $10^{5}$ macrophages in $1 \mathrm{ml}$ of "medium" were mixed with either methylcellulose (Dow Corning Co., Midland, MI) or agar (Difco Laboratories, Detroit, MI), and seeded into 35-mm culture dishes (Lux, Miles Laboratories, Naperville, IL). "Medium" consisted of Iscove's Modified Dulbecco medium (Gibco Laboratories) supplemented with $10 \mu \mathrm{g} / \mathrm{ml}$ bovine serum albumin (Sigma Chemical Co.), $10^{-4} \mathrm{M} \beta$-mercaptoethanol (Sigma Chemical Co.), and 30\% heat-inactivated fetal bovine serum (Gibco Laboratories). Methylcellulose was used at a final concentration of $0.8 \%$ and agar at $0.3 \%$. Cultures were incubated $\left(37^{\circ} \mathrm{C}, 5 \% \mathrm{CO}_{2}: 95 \%\right.$ air) for $10 \mathrm{~d}$, with cluster formation ( $>4$ cells implying $>2$ rounds of replication) scored at days 1,7 , and 10 . To accomplish this, the number of clusters within 10 standard sized regions (representing $4 \mathrm{~cm}^{2}$ ) on each of two dishes was counted. To exclude the possibility that cell aggregation was responsible for the clusters observed, in several cultures $\left[{ }^{3} \mathrm{H}\right]$ thymidine was added at the time of seeding to verify that all nuclei in a cluster had synthesized DNA. The cells were fixed in situ with methanol:acetic acid, 3:1, after culture in agar for $10 \mathrm{~d}$, and nuclei that had synthesized DNA were demonstrated by autoradiography. To establish that cells forming clusters were macrophages, in several cultures these cells were assessed for their ability to phagocytose iron, and to bind and phagocytose IgG-coated as well as $\mathrm{C}_{3} \mathrm{~b}$-IgM-coated ox erythrocytes prepared as previously described (14).

Statistical analysis. Comparisons of results from normals with those of the several patient groups were carried out using the Wilcoxon rank order test with the confidence limits adjusted for multiple comparisons.

\section{Results}

DNA synthesis by alveolar macrophages. Alveolar macrophages were clearly capable of actively synthesizing DNA (Fig. 1). Confirmation that these cells were alveolar macrophages was provided by their morphology, the ability of the cells to rapidly phagocytose opsonized iron ( $>90 \%$ of labeled cells in $30 \mathrm{~min}$ ), and the presence of positive staining for nonspecific esterase ( $92 \pm 5 \%$ on parallel slides).

In normal individuals, less than 1 in 200 alveolar macrophages was actively synthesizing DNA during the $16 \mathrm{~h}$ that $\left[{ }^{3} \mathrm{H}\right]$ thymidine was present in the cultures. In contrast, in individuals with chronic lung inflammation, this proportion was increased 4- to 15-fold (Fig. 2). Individuals with an average 5 pack-year history of smoking had an approximately fourfold increase in the percentage of macrophages synthesizing DNA compared with normals who did not smoke $(P<0.01)$. Patients with lung disorders characterized by chronic inflammation such as IPF, sarcoidosis, histiocytosis $\mathrm{X}$, or inorganic dust exposure had a 10- to 15-fold increase in the percentage of macrophages undergoing DNA synthesis compared with normals $(P<0.01$, all comparisons). In these patients, neither smoking nor therapy status (data not shown) had a significant effect on the proportion of labeled nuclei $(P>0.2$, all comparisons). Thus, in chronic 


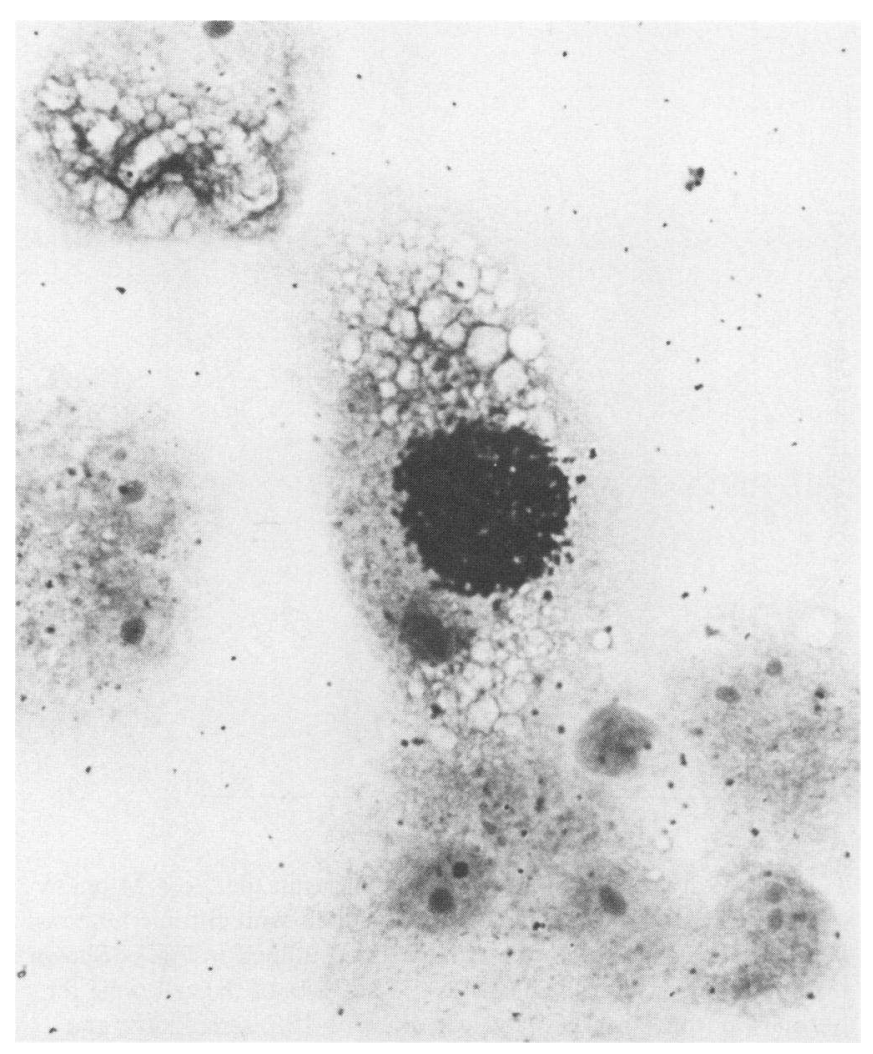

Figure 1. Autoradiographic demonstration of DNA synthesis by alveolar macrophages. A cytocentrifuge preparation of alveolar macrophages from a patient with idiopathic pulmonary fibrosis that had been cultured $\left(37^{\circ} \mathrm{C}, 16 \mathrm{~h}\right)$ in DMEM $+10 \%$ autologous serum containing $\left[{ }^{3} \mathrm{H}\right]$ thymidine are shown. The slides were processed for autoradiography and then stained with Giemsa blood stain. A representative field demonstrating the densely labeled nucleus of a macrophage in $S$ phase is shown $(\times 800)$.

lung inflammation, an increased proportion of alveolar macrophages actively synthesized DNA, suggesting a significant number of these cells were in $\mathrm{S}$ phase in the process of replication.

DNA content of macrophages from individuals with chronic lung inflammation. Analysis of the DNA content of alveolar macrophages immediately after their removal from the lower respiratory tract demonstrated that individuals with chronic lung inflammation clearly contained cells in all phases of the cell cycle (Fig. 3). Using cycling log phase fibroblasts $\left(G_{1}, S, G_{2}\right.$ $+M$, all present) and noncycling, density arrested fibroblasts $\left(G_{1}\right.$ only) as internal standards for calibrating DNA content, flow cytometric evaluation of macrophages indicated that most patients with chronic lung inflammation demonstrated the typical pattern for cycling log phase cells. This not only confirmed the autoradiographic finding of macrophages in $S$ phase, but also demonstrated that significant numbers of alveolar macrophages recovered from individuals with chronic lung inflammation were in $\mathrm{G}_{2}+\mathrm{M}$ (Fig. $3 C$ and $D$ ). In contrast, mac-

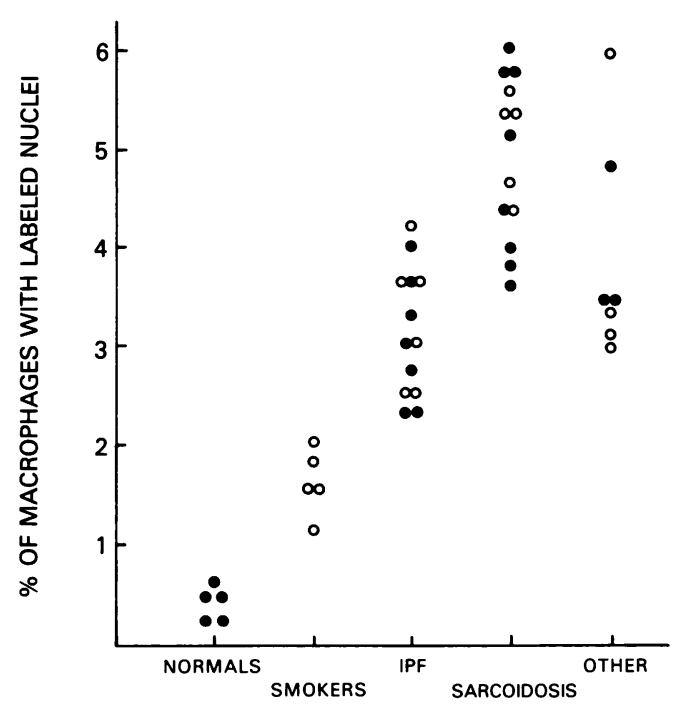

Figure 2. DNA synthesis by alveolar macrophages from normal individuals and individuals with chronic lung inflammation. Alveolar macrophages were cultured as described for Fig. 1. The percentages of labeled alveolar macrophage nuclei for normals, normal smokers, and patients with IPF, sarcoidosis, and other chronic interstitial lung disorders ("other;" see Methods for list) are shown. Nonsmokers are indicated as "๑" and smokers as "o".

rophages from normal individuals had the pattern consistent with a noncycling or very slowly cycling population (Fig. $3 \mathrm{~A}$, $B)$. Evidence that the analyzed population was alveolar macrophages $(\geq 98 \%)$ and not other cell types, such as lymphocytes, neutrophils, or eosinophils, included morphology, histochemistry, and ability to phagocytose (data not shown).

Attaining the degree of cell purity required to evaluate macrophage DNA content by FACS analysis necessitated the evaluation of only the larger half of the macrophage population. Since on the average the replicating macrophages were larger than the nonreplicating macrophages, it is likely that the analyzed population contained the majority of the alveolar macrophages in the $S+\left(G_{2}+M\right)$ phases of the cell cycle, i.e., that the estimated proportion of macrophages replicating was an overestimate of the actual number of macrophages replicating. Within this framework, while nonsmoking normal individuals had only $\sim 1-2 \%$ of their alveolar macrophages in $\mathrm{G}_{2}+\mathbf{M}$, normal smokers had a twofold increase in this value (Fig. 4). In addition, patients with a variety of inflammatory lung disorders had a three- to sevenfold increase in the percentage of macrophages in $\mathrm{G}_{2}+\mathrm{M}$. Moreover, the FACS analysis of DNA content demonstrated that while nonsmoking normals had only $1 \%$ of their macrophages in $\mathrm{S}$ phase, values for smokers were increased about twofold, IPF about sixfold, and sarcoidosis approximately 10-fold (data not shown). These relative increases in the proportion of macrophages in $\mathrm{S}$ phase from patients compared with normals were in agreement with the values obtained by autoradiographic analysis of the entire adherent cell population, and 

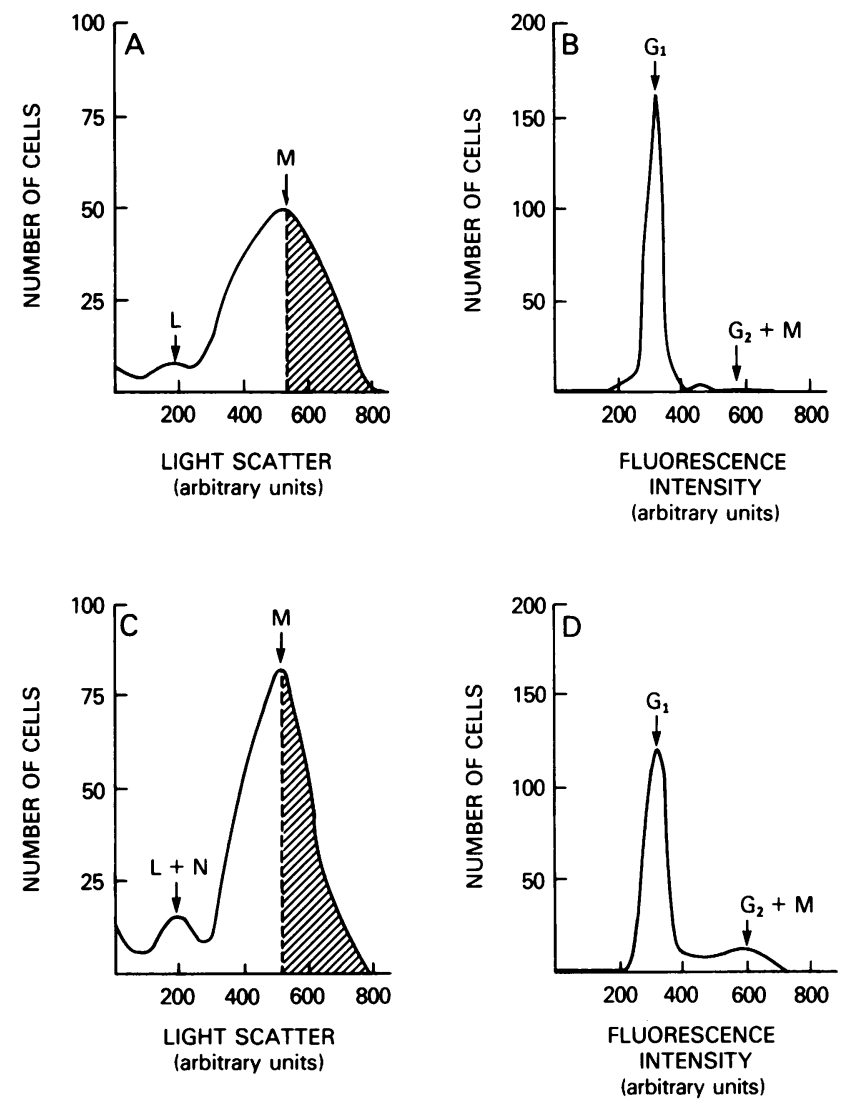

Figure 3. Flow cytometric analysis of the DNA content of alveolar macrophages. Lavage cells $\left(10^{6}\right)$ were fixed in ethanol, stained with mithramycin, and analyzed for forward light scatter. The peak corresponding to the population of cells scattering the most light was identified (with lavage cells, this peak is predominantly alveolar macrophages) and the quantity of light scatter units representing the center of the peak was determined. The cells with light scatter units greater than this value were then analyzed for DNA content. Sorting of these cells and subsequent morphologic evaluation demonstrated this population was comprised of $>98 \%$ alveolar macrophages in all cases. $(A)$ Light scatter analysis of bronchoalveolar lavage cells recovered from a normal individual. $L$, center of region comprised of lymphocytes; $M$, center of region comprised of alveolar macrophages. The hatched area indicates the cell population chosen for DNA analysis. In a normal individual, $>90 \%$ of the lavage cells are alveolar macrophages. Abscissa, arbitrary units of forward light scatter; ordinate, number of cells in each of 800 channels representing increasing light scatter units. $(B)$ DNA content of alveolar macrophages of the normal individual represented in $A$. Abscissa, intensity of fluorescence, which is proportional to DNA content; ordinate, number of cells in each of 800 channels representing increasing DNA content. The DNA content of alveolar macrophages in the $G_{1}$ and $G_{2}+M$ phases of the cell cycle are shown; cells in the $S$ phase fall between these regions. The fluorescence intensity values corresponding to the $G_{1}$ and $G_{2}$ $+M$ phases of the cell cycle were determined using density arrested and log phase human fetal lung (HFL-1) fibroblasts as a standard (density arrested HFL-1 cells are normal diploid human fibroblasts). In normal individuals, almost all alveolar macrophages are in the $\mathbf{G}_{1}$

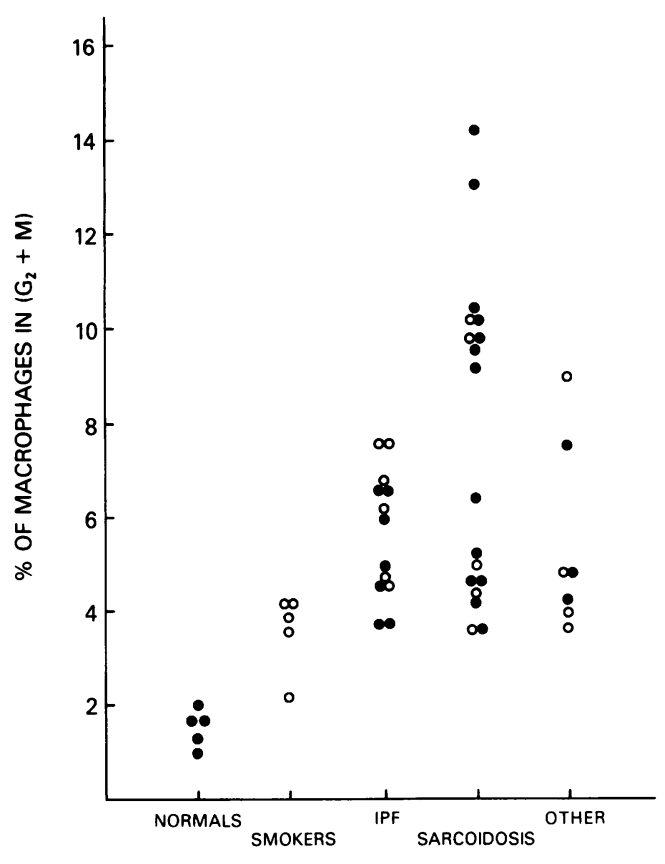

Figure 4. Proportion of alveolar macrophages in the $G_{2}+M$ phase of the cell cycle from normals and individuals with chronic lung inflammation. Lavage cells were analyzed as outlined in Fig. 3. Shown is the proportion of cells in the $G_{2}+M$ phases of the cell cycle for normals, normal smokers, and patients with IPF, sarcoidosis, and other chronic interstitial lung disorders ("other," see Methods for list). Indicated are the values for nonsmokers ( $\bullet$ ) and smokers (0).

together with the clear presence of macrophages in $G_{2}+M$, argued against the possibility that the autoradiographic findings of $\left[{ }^{3} \mathrm{H}\right]$ thymidine incorporation reflected only DNA repair and not replication-directed DNA synthesis.

Demonstration of alveolar macrophages in the M-phase of replication. Confirmation that the alveolar macrophages traversed $G_{2}$ into the $M$ phase of the cell cycle was provided both by light microscopic analysis of cells cultured with amounts of colchicine that blocked cytokinesis, and by ultrastructural analysis of lung biopsy specimens from patients with chronic inflammatory lung disorders (Figs. 5, 6). Examples of metaphase cells were rare in normals, although they could always be found. Qualitative analysis suggested that the metaphase cells were far more frequent in the patients with chronic lung inflammation than in normals (Fig. 5), but due to variable cell losses during processing, this technique could not be used quantitatively. Ul-

phase of the cell cycle. $(C)$ Similar to $A$, but for a patient with idiopathic pulmonary fibrosis. L, lymphocytes; N, neutrophils; M, alveolar macrophages. The majority of the cells recovered were alveolar macrophages. $(D)$ Similar to $B$, but for the patient shown in $C$. Note that a significant number of the alveolar macrophages have a tetraploid DNA content, i.e., macrophages in the $G_{2}+M$ phase of the cell cycle. 


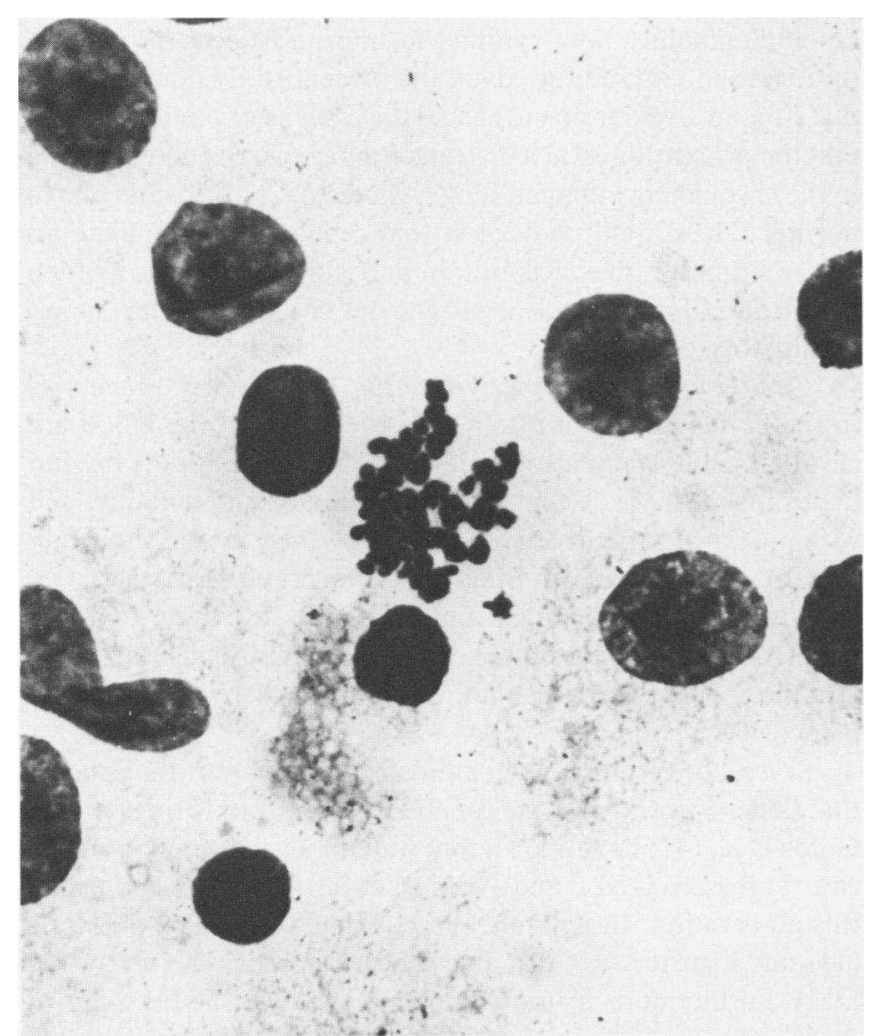

Figure 5. Light microscopic demonstration of alveolar macrophages in metaphase. Alveolar macrophages were cultured $\left(37^{\circ} \mathrm{C}, 48 \mathrm{~h}\right)$ on slides in the presence of the mitotic inhibitor colchicine. Cells were swollen in hypotonic solution, fixed, and stained with a modified Wright Giemsa stain. A metaphase macrophage from a patient with IPF is shown $(\times 500)$.

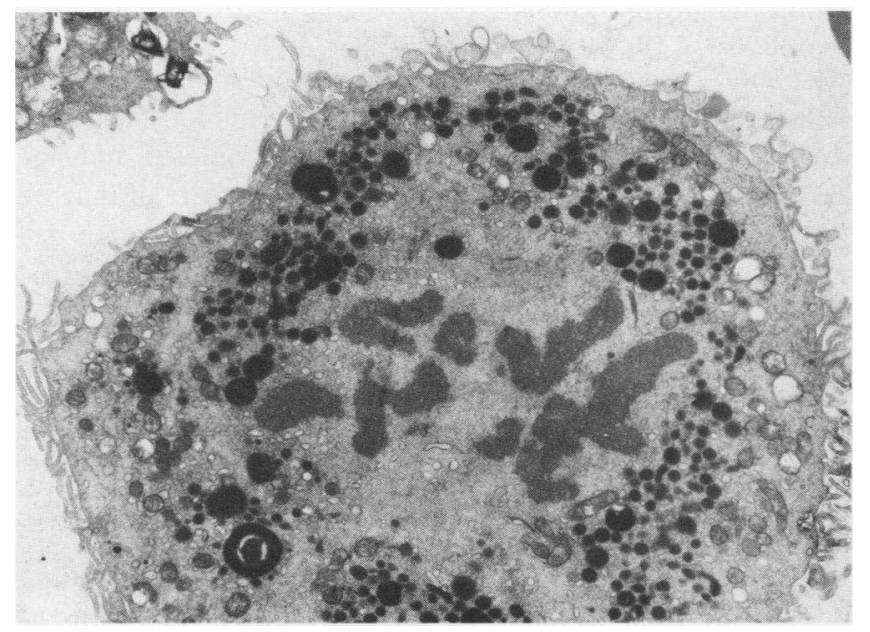

Figure 6. Ultrastructural demonstration of an alveolar macrophage in metaphase, in an open lung biopsy of a patient with sarcoidosis $(\times 6,000)$. trastructural analysis of several lung biopsies from patients with inflammatory lung disorders corroborated the presence of macrophages in metaphase (example shown in Fig. 6). Thus, alveolar macrophages were capable of traversing all phases of the cell cycle, strongly supporting the concept that the autoradiographic and flow cytometric findings reflected cells in the process of replicating.

Macrophage replication in vitro. While the demonstration that alveolar macrophages entered $M$ phase established that these cells were in the process of replication, formal proof that they could undergo cytokinesis and divide was provided by their ability to form clusters in anchorage-independent culture. Analysis of macrophage cultures $1 \mathbf{d}$ after seeding in methylcellulose or agar revealed nearly all of the cells were single with occasional doublets. In marked contrast, after 7-10 d, a small proportion of the cells had undergone several rounds of replication resulting in clusters of 4-32 cells (Fig. 7). These cells were identified as macrophages morphologically and by their ability to phagocytose iron as well as ox erythrocytes via the $\mathrm{Fc}$ or $\mathrm{C}_{3} \mathrm{~b}$ receptor, thus excluding the possibility that they were lymphocytes or fibroblasts. In addition, autoradiographic analysis of clusters that

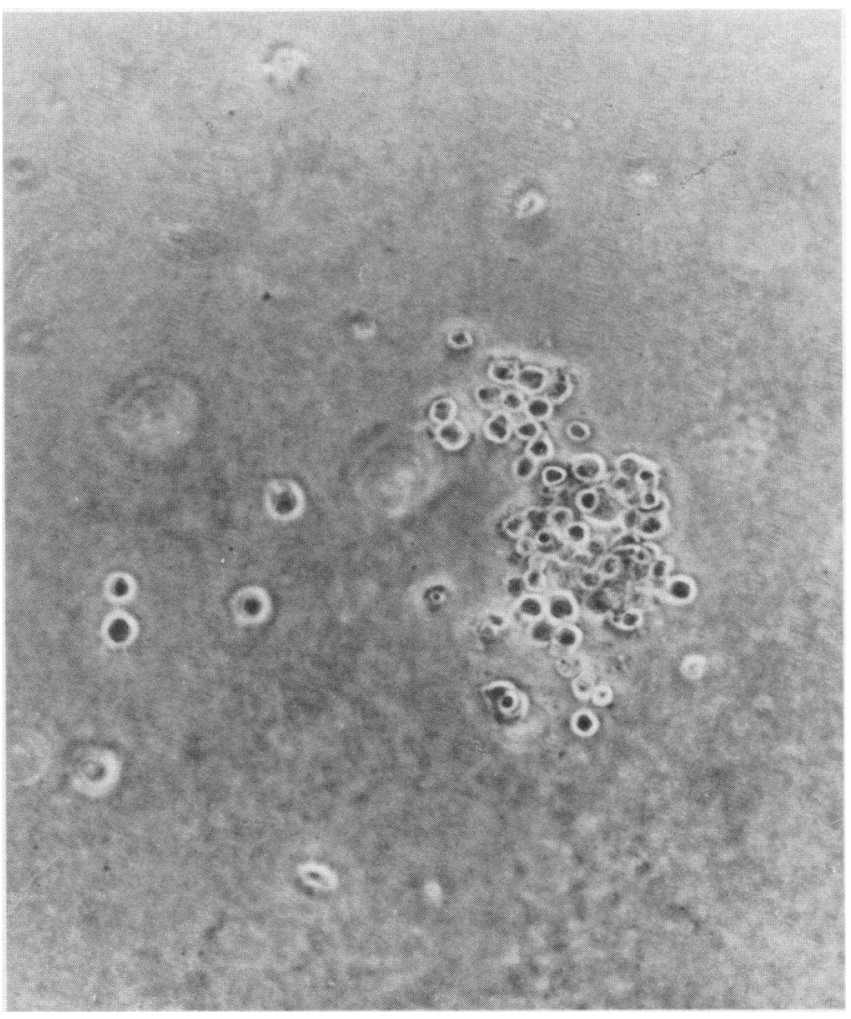

Figure 7. Cluster formation by alveolar macrophages replicating in culture. Bronchoalveolar lavage cells $\left(10^{5} /\right.$ dish) were cultured in methylcellulose as described in Methods. A cluster of macrophages on day 9 of culture from a patient with asbestosis is shown. $(\times 100)$. 
were formed with $\left[{ }^{3} \mathrm{H}\right]$ thymidine added to the cultures revealed that all of the cells in $>90 \%$ of clusters had labeled nuclei. These findings provided a clear demonstration of the ability of alveolar macrophages to replicate.

Employing this anchorage-independent culture system, it was apparent that alveolar macrophages from individuals with chronic lung inflammation formed a substantially increased number of clusters compared with normals (Fig. 8). In this regard, macrophages from normal, nonsmokers formed 10-50 clusters per dish. In marked contrast, there was up to a sixfold increase in this value for patients with chronic lung inflammation, with 18 of 26 individuals above the normal range ( $P$ $<0.05$, all comparisons with normals). These findings were in concert with the autoradiographic and flow cytometric findings and indicated that an increased proportion of the alveolar macrophages from individuals with chronic lung inflammation were actively replicating compared with normals.

\section{Discussion}

The increased number of mononuclear phagocytes characteristic of the chronic inflammatory state can theoretically result from an increased rate of recruitment of these cells from the blood, from a decreased rate of efflux (including cell death) from the lung, or from local replication. Based upon a combination of

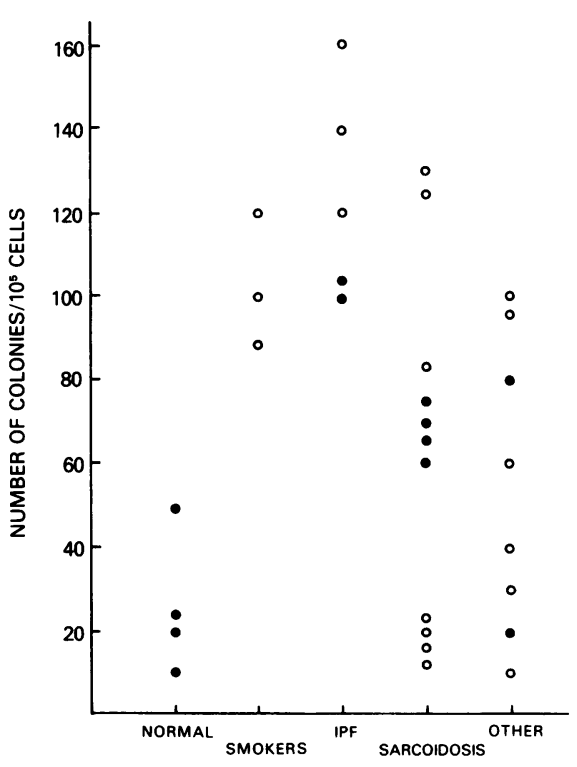

Figure 8. Comparison of in vitro replication of alveolar macrophages from normal individuals and individuals with chronic lung inflammation. Lavage cells from normals, normal smokers, and patients with IPF, sarcoidosis, and other chronic interstitial lung disorders ("other," see Methods for list) were seeded in methylcellulose as described in Methods. Following culture $\left(37^{\circ} \mathrm{C}, 10 \mathrm{~d}\right)$, the number of clusters (defined as $>4$ cells) were counted. The number of clusters formed by alveolar macrophages from the various groups are shown. Nonsmokers are indicated as "॰" and smokers as " $\circ . "$ autoradiographic, flow cytometric, morphological, ultrastructural, and in vitro culture data, the present study demonstrates that human alveolar macrophages are capable of replicating and that the proportion of alveolar macrophages actively replicating in the chronically inflamed lung is increased 2- to 15 -fold above normal. These findings suggest that replication within the alveolar structures may account, in part, for the expansion of the population of mononuclear phagocytes observed in chronic inflammatory disorders.

Can tissue macrophages replicate? Although their precursors in the bone marrow and to a limited extent, in the blood are clearly capable of replication (38-40), one concept of the human tissue macrophage is that it is a terminally differentiated cell with little, if any, ability to replicate. However, the current study presents evidence that human tissue macrophages, at least in the lung, are present in all phases of the cell cycle and can undergo several rounds of replication in vitro, strongly suggesting that the concept of this cell not having the potential to replicate is incorrect.

Several other human and animal studies support the concept that tissue macrophages are capable of replicating. For example, Golde et al. (41) have shown that human alveolar macrophages can synthesize DNA, and Arnoux et al. (42) have confirmed this observation. In animals, there is data from mice (43), rats (44), and hamsters (45) that alveolar macrophages can synthesize DNA. Furthermore, macrophage DNA synthesis has been shown during murine liver regeneration following partial hepatectomy (46) and in chronic exudates in the pleural (47) and peritoneal cavities (48). Moreover, several studies have shown that bovine (49), murine (50), and hamster (45) macrophages not only are capable of DNA synthesis, but also are able to divide.

Expansion of the macrophage population in chronic inflammatory lung diseases. Several lines of evidence have shown that there are increased numbers of mononuclear phagocytes within the alveolar structures in conditions characterized by chronic inflammation in the lower respiratory tract. First, numerous morphological studies of biopsy and postmortem material from patients with a variety of inflammatory lung conditions including sarcoidosis, IPF, histiocytosis $\mathrm{X}$, the pneumoconioses, and cigarette smoking suggest there are increased numbers of macrophages within the lower respiratory tract (18-24). Second, rigorous demonstration of increased numbers of alveolar macrophages by morphometry has been performed in several animal models of inflammatory lung disorders (51-53) and in small numbers of human smokers (54). Finally, quantitation of the numbers of macrophages recovered by bronchoalveolar lavage indicates that individuals with chronic lung inflammation have a substantial increase in the number of macrophages in the alveolar compartment accessible to that procedure (55).

To fully understand the dynamics of this increase in the alveolar macrophage population in conditions associated with chronic inflammation of the lower respiratory tract, the relative rates of three separate processes must be quantified: $(a)$ the rate of influx of blood monocytes into the lung parenchyma; $(b)$ the rate of efflux of macrophages from the lung including the rate 
of cell death; and $(c)$ the rate of macrophage replication within the lower respiratory tract.

Monocyte influx. Quantitation of the rate of monocyte influx into the human lung has not been carried out. However, indirect evidence that the process occurs includes bone marrow transplant studies in which donor phenotype macrophages are found in the recipient's alveolar structures (56), and the presence of increased numbers of immature monocyte-macrophages in the lungs of patients with active sarcoidosis, a group of patients known to have lung $\mathrm{T}$-lymphocytes that spontaneously release a monocyte chemotactic factor $(57,58)$. In addition to these indirect human studies, careful quantification of the rate of mononuclear phagocyte influx in lung has been performed in mice by Blusse Van Oud Alblas and co-workers (43). In this acute inflammatory murine model, the rate of monocyte influx is increased up to sevenfold above the steady state rate. Taken together, these human and animal studies support the concept that in normal circumstances, blood monocytes move into the lung at some steady rate, and that this rate increases in inflammation.

Macrophage efflux. No information is available in humans regarding efflux rate or cell death in normal circumstances, nor in acute or chronic inflammation. However, it is known that alveolar macrophage efflux rates are increased up to twofold above the steady state rate in a murine model of acute inflammation (43).

Macrophage replication. In addition to the present study, the findings of Golde and co-workers (41), and Arnoux et al. (42), suggest that in humans, the proportion of alveolar macrophages actively synthesizing DNA in the steady state is very low. In accord with these findings, animal studies by Blusse Van Oud Alblas et al. (43) as well as Evans and Bils (59) indicate a low steady state rate of macrophage replication. Consistent with our observations, several studies demonstrate a substantial increase in the rate of macrophage replication during inflammation. In humans, there is evidence suggesting that in cigarette smokers and in nonsmoking patients with sarcoidosis, the proportion of alveolar macrophages synthesizing DNA increases above the low steady state proportion found in normals (41, 42). In an acute inflammatory murine model, while the quantitative data suggests that increased cell influx accounts for most of the increase in the mononuclear phagocyte population within the lung, there was also a modest but clear increase in local alveolar macrophage production observed (43). In addition, in a subacute animal model of inflammation, Adamson and Bowden (17) not only observed an increase in the number of mononuclear phagocytes synthesizing DNA, but also found that epithelial lining fluid from these animals was able to stimulate mononuclear phagocyte replication when administered into the lower respiratory tract of healthy mice.

Effect of glucocorticoid therapy on alveolar macrophage replication. Glucocorticoid therapy had no demonstrable effect on the proportion of alveolar macrophages actively replicating in the two large patient groups evaluated, IPF and sarcoidosis. This is important in view of the well-documented ability of gluco- corticoids to modulate mononuclear phagocyte replication in animals (60-62). The present study, however, does not exclude an effect of glucocorticoids on human alveolar macrophage replication. To directly address this issue, longitudinal studies of individual patients before, during, and after glucocorticoid therapy are necessary.

Potential role of alveolar macrophage replication in chronic lung inflammation. While human alveolar macrophages are able to synthesize DNA and replicate, only a small proportion of the total macrophage population does so at any point in time. The properties of the subpopulation of the lung mononuclear phagocytes that replicate, and the signals in vivo or in vitro that regulate their replication are unknown. In this regard, both macrophages and lymphocytes are known to release colony stimulating factor(s) as well as other growth factors that may augment macrophage replication. In addition, other lung parenchymal cells may be potential sources of growth factors for alveolar macrophages (63). Independent of the mechanism, documentation of the ability of human alveolar macrophages to replicate, along with the observation of a large increase in the proportion of cells replicating in conditions characterized by chronic lung inflammation, suggests a possible role for replication in the expansion of the entire mononuclear phagocyte population. Alternatively, replication may provide a mechanism for expanding specific subpopulations of mononuclear phagocytes within the chronically inflamed alveolar structures rather than expanding the entire population. For example, ultrastructural evaluation of lung biopsies from patients with histiocytosis $\mathrm{X}$ indicates that one particular subpopulation of mononuclear phagocyte, the Langerhans cell, is able to replicate (27). Thus, in the chronic inflammatory state, mononuclear phagocyte replication may be influential in altering the number and types of mononuclear phagocytes present and hence, the nature of the inflammatory microenvironment.

\section{Acknowledgments}

We wish to thank Bob Cunningham and Steve Goodman for expert assistance in operating the FACs.

\section{References}

1. Mackaness, M. B. 1962. Cellular resistance to infection. J. Exp. Med. 116:381-406.

2. Van Furth, R., and Z. A. Cohn. 1968. The origin and kinetics of mononuclear phagocytes. J. Exp. Med. 128:415-435.

3. Mononuclear Phagocytes: Functional Aspects of Mononuclear Phagocytes. 1980. Van Furth, R., editor. Kluwer Nijhoff Publishing, Boston.

4. Hunninghake, G. W., J. E. Gadek, S. V. Szapiel, I. J. Strumpf, O. Kawanami, V. J. Ferrans, B. A. Keogh, and R. G. Crystal. 1980. The human alveolar macrophage. Methods Cell Biol. 21:95-112.

5. Johnston, R. B., Jr., C. A. Godzik, and Z. A. Cohn. 1978. Increased superoxide anion production by immunologically activated and chemically elicited macrophages. J. Exp. Med. 148:115-127.

6. Hoidal, J. R., G. D. Beall, and J. E. Repine. 1979. Production 
of hydroxyl radical by human alveolar macrophages. Infect. Immun. 26:1088-1094.

7. Werb, Z., and S. Gordon. 1975. Secretion of a specific collagenase by stimulated macrophages. J. Exp. Med. 142:346-360.

8. Werb, Z., and S. Gordon. 1975. Elastase secretion by stimulated macrophages. J. Exp. Med. 142:361-377.

9. Hunninghake, G. W., J. E. Gadek, H. M. Fales, and R. G. Crystal. 1980. Human alveolar macrophage-derived chemotactic factor for neutrophils: stimuli and partial characterization. J. Clin. Invest. 66:473483.

10. Rennard, S. I., G. W. Hunninghake, P. B. Bitterman, and R. G. Crystal. 1981. Production of fibronectin by the human alveolar macrophage: mechanism for the recruitment of fibroblasts to sites of tissue injury in interstitial lung diseases. Proc. Natl. Acad. Sci. USA. 78:7147-7151.

11. Leibovich, S. J., and R. Ross. 1976. A macrophage-dependent factor that stimulates the proliferation of fibroblasts in vitro. J. Pathol. 84:501-513.

12. DeLustro, F., G. K. Sherer, and E. C. LeRoy. 1980. Human monocyte stimulation of fibroblast growth by a soluble mediator(s). $J$. Reticuloendothel. Soc. 28:519-532.

13. Schmidt, J. A., S. B. Mizel, D. Cohen, and I. Green. 1982. Interleukin-1, a potential regulator of fibroblast proliferation. J. Immunol. 128:2177-2182.

14. Bitterman, P. B., S. I. Rennard, G. W. Hunninghake, and R. G. Crystal. 1982. Human alveolar macrophage growth factor for fibroblasts: regulation and partial characterization. J. Clin. Invest. 70:806822.

15. Bitterman, P. B., S. I. Rennard, S. Adelberg, and R. G. Crystal. 1983. Role of fibronectin as a growth factor for fibroblasts. J. Cell Biol. 97:1925-1932.

16. Blusse Van Oud Alblas, A., and R. VanFurth. 1979. The origin, kinetics, and characteristics of pulmonary macrophages in the normal steady state. J. Exp. Med. 149:1504-1518.

17. Adamson, I. Y. R., and D. H. Bowden. 1982. Chemotactic and mitogenic components of the alveolar macrophage response to particles and neutrophil chemoattractant. Am. J. Pathol. 109:71-77.

18. Valdivia, E., G. Hensley, J. Wu, E. P. LeRoy, and W. Jaeschke. 1977. Morphology and pathogenesis of desquamative interstitial pneumonitis. Thorax. 32:7-18.

19. Carrington, C. B., E. A. Gaensler, J. P. Mikos, A. W. Schachter, G. W. Burke, and A. M. Goff. 1976. Structure and function in sarcoidosis. Ann. NY Acad. Sci. 278:265-283.

20. Scadding, J. G., and K. F. W. Hinson. 1967. Diffuse fibrosing alveolitis (diffuse interstitial fibrosis of the lungs): correlation of histology at biopsy with progrosis. Thorax. 22:291-304.

21. Spencer, H. 1967. Interstitial pneumonia. Ann. Rev. Med. 18:423442.

22. Auerbach, O., A. P. Stout, E. C. Hammond, and L. Garfinkel. 1963. Smoking habits and age in relation to pulmonary changes: rupture of alveolar septums, fibrosis, and thickening of walls of small arteries and arterioles. N. Engl. J. Med. 269:1045-1054.

23. Hoidal, J. R., R. B. Fox, P. A. LeMarbe, R. Parri, and J. E. Repine. 1981. Altered oxidative metebolic responses in vitro of alveolar macrophages from asymptomatic cigarette smokers. Am. Rev. Respir. Dis. 123:85-89.

24. Hunninghake, G. W., and R. G. Crystal. 1983. Cigarette smoking and lung destruction: accumulation of neutrophils in the lungs of cigarette smokers. Am. Rev. Respir. Dis. 128:833-838.

25. Crystal, R. G., J. D. Fulmer, W. C. Roberts, M. L. Moss, B. R.
Line, and H. Y. Reynolds. 1976. Idiopathic pulmonary fibrosis: clinical, histologic, radiographic, physiologic, scintigraphic, cytologic, and biochemical aspects. Ann. Intern. Med. 85:769-788.

26. Siltzbach, L. E. 1980. Sarcoidosis. In Pulmonary Diseases and Disorders. A. P. Fishman, editor. McGraw Hill Book Co., New York. 889-908.

27. Basset, F., B. Corrin, H. Spencer, J. Lacronique, C. Roth, P. Soler, J.-P. Battesti, R. Georges, and J. Chretien. 1978. Pulmonary histiocytosis X. Am. Rev. Respir. Dis. 118:811-820.

28. Becklake, M. R. 1983. Asbestosis-related diseases of the lung and pleura. Am. Rev. Respir. Dis. 126:187-194.

29. Merchant, J. A. 1983. Coal workers' pneumoconiosis. In Environmental and Occupational Medicine. W. N. Rom, editor. Little Brown, Boston. 183-196.

30. Hunninghake, G. W., J. E. Gadek, O. Kawanami, V. J. Ferrans, and R. G. Crystal. 1979. Inflammatory and immune processes in the human lung in health and disease: evaluation by bronchoalveolar lavage. Am. J. Pathol. 97:149-206.

31. Kaplow, L. S. 1981. Cytochemical identification of mononuclear macrophages. In Manual of Macrophage Methodology. H. B. Herscowitz, H. T. Holden, J. A. Bellanti, A. Chaffar, editors. Marcel Dekker, New York. 199-207.

32. Baserga, R., and D. Malamud. 1969. Autoradiography: Techniques and Applications. Harper and Row, New York.

33. Crissman, H. A., and R. A. Tobey. 1974. Cell-cycle analysis in 20 minutes. Science (Wash. DC). 184:1297-1298.

34. Flow Cytometry and Sorting. 1979. M. R. Melamed, P. F. Mullaney, and M. L. Mendelsohn, editors. Wiley, New York.

35. Worton, R. G., and C. Duff. 1979. Karyotyping. In Methods in Enzymology, Volume LVIII, Cell Culture. W. B. Jakoby, and I. H. Pastan, editors. Academic Press, New York. 322-344.

36. Kawanami, O., V. J. Ferrans, W. C. Roberts, R. G. Crystal, and J. D. Fulmer. 1978. Anchoring fibrils: a new connective tissue structure in fibrotic lung disease. Am. J. Pathol. 92:389-410.

37. Metcalf, D. 1970. Studies in colony formation in vitro by mouse bone marrow cells. II. Action of colony stimulating factor. J. Cell Physiol. 76:89-99.

38. Burgess, A. W., and D. Metcalf. 1980. The nature and action of granulocyte-macrophage colony stimulating factors. Blood. 56:947958 .

39. Van der Meer, J. W. M., J. S. Van de Gevel, R. H. J. Beelen, D. Fluitsma, E. C. M. Hoetsmit, and R. Van Furth. 1980. Culture of human bone marrow in the Teflon culture bag: identification of the human monoblast. J. Reticuloendothel. Soc. 32:355-369.

40. Salahuddin, S. Z., P. D. Markham, and R. C. Gallo. 1982. Establishment of long-term monocyte suspension cultures from normal human peripheral blood. J. Exp. Med. 155:1842-1857.

41. Golde, D. W., L. A. Byers, and T. N. Finley. 1974. Proliferative capacity of human alveolar macrophages. Nature (Lond.). 247:373-375.

42. Arnoux, A., R. Masse, and J. Chretien. 1983. Evidence of an increased persistent mitotic activity in cells recovered by bronchoalveolar lavage in sarcoidosis. In Sarcoidosis and Other Granulomatous Disorders. J. Chretien, J. Marsac, and J. C. Saltiel, editors. Pergamon Press, New York. 50-54.

43. Blusse Van Oud Alblas, A., B. VanderLinden-Schrever, and $\mathbf{R}$. VanFurth. 1983. Origin and kinetics of pulmonary macrophages during an inflammatory reaction induced by intra-alveolar administration of aerosolized heat-killed BCG. Am. Rev. Respir. Dis. 128:276-281.

44. Evans, M. J., L. J. Cabral, R. J. Stephens, and G. Freeman. 
1973. Cell division of alveolar macrophages in rat lung following exposure to $\mathrm{NO}_{2}$. Am. J. Pathol. 70:199-207.

45. Lin H.-S., C. Kuhn, and T.-T. Kuo. 1975. Clonal growth of hamster free alveolar cells in soft agar. J. Exp. Med. 142:877-886.

46. Edwards, J. L., and A. Koch. 1964. Parenchymal and littoral cell proliferation during liver regeneration. Lab. Invest. 13:32-43.

47. Meuret, G., O. Schildknecht, P. Joder, and H. Senn. 1980. Proliferation activity and bacteriostatic potential of human blood monocytes, macrophages in pleural effusions, ascites, and of alveolar macrophages. Blut. 40:17-25.

48. Lin, H.-S., and C. C. Stewart. 1974. Peritoneal exudate cells. Growth requirement of cells capable of forming colonies in soft agar. J. Cell. Physiol. 83:369-378.

49. McGuire, R. L., and L. A. Babiuk. 1982. In vitro culture characteristics of bovine alveolar macrophages. J. Reticuloendothel. Soc. 31:251-260.

50. Soderland, S. C., and Y. Naum. 1973. Growth of pulmonary alveolar macrophages in vitro. Nature (Lond.). 245:150-152.

51. Thet, L. A., and J. D. Crapo. 1982. Morphometry of ultrastructural changes in the lung due to radiation injury. Am. Rev. Respir. Dis. 125(pt. 2):229.

52. Crapo, J. D., M. Peters-Golden, J. Marsh-Salin, and J. S. Shelburne. 1978. Pathologic changes in the lungs of oxygen-adapted rats: a morphometric analysis. Lab. Invest. 39:640-653.

53. Hayatdavoudi, G., J. J. O'Neil, B. E. Barry, B. A. Freeman, and J. D. Crapo. 1981. Pulmonary injury in rats following continuous exposure to $60 \% \mathrm{O}_{2}$ for 7 days. J. Appl. Physiol. 51:1220-1231.

54. Crapo, J. D., B. E. Barry, P. Gehr, M. Bachofen, and E. R. Weibel. 1982. Cell number and cell characteristics of the normal human lung. Am. Rev. Respir. Dis. 125:740-745.
55. Crystal, R. G., P. B. Bitterman, S. I. Rennard, and B. A. Keogh. 1983. Interstitial lung disease of unknown etiology: disorders characterized by chronic inflammation of the lower respiratory tract. $N$. Engl. J. Med. 310(pts. 1 and 2):154-166, 235-244.

56. Thomas, E. D., R. E. Ramberg, G. E. Sale, R. S. Sparks, and D. W. Golde. 1976. Direct evidence of a bone marrow-origin of the alveolar macrophage in man. Science (Wash. DC). 192:1016-1018.

57. Hunninghake, G. W., J. E. Gadek, R. C. Young, Jr., O. Kawanami, V. J. Ferrans, and R. G. Crystal. 1980. Maintenance of granuloma formation in pulmonary sarcoidosis by T-lymphocytes within the lung. N. Engl. J. Med. 302:594-598.

58. Hance, A., S. Douches, R. Winchester, and R. Crystal. 1984. Cell surface characterization of alveolar macrophages participating in the alveolitis of active pulmonary sarcoidosis. Clin. Res. 34:430A.

59. Evans, M. J., and R. F. Bils. 1969. Identification of cells labelled with activated thymidine in the pulmonary alveolar walls of the mouse. Am. Rev. Respir. Dis. 100:372-378.

60. Werb, Z. 1978. Biochemical actions of glucocorticoids on macrophages in culture. Specific inhibition of elastase, collagenase, and plasminogen activator and effects on other metabolic functions. $J$. Exp. Med. 147:1695-1712.

61. Neumann, C., and C. Sorg. 1983. Regulation of plasminogen activator secretion, interferon induction and proliferation in murine macrophages. Eur. J. Immunol. 13:143-147.

62. Duncan, M. R., J. R. Sadlik, and J. W. Hidden. 1982. Glucocorticoid modulation of lymphokine induced macrophage proliferation. Cell Immunol. 67:23-36.

63. Burgess, A. W., and D. Metcalf. 1980. The nature and action of granulocyte-macrophage colony stimulating factors. Blood. 56:947958. 